\title{
Bupropion abuse and overdose
}

\author{
Nathan Stall MD, Jesse Godwin MD, David Juurlink MD PhD
}

\section{Bupropion is a commonly used anti- depressant and smoking cessation aid}

Bupropion is used widely as a smoking cessation aid and antidepressant and is available in immediate- and extendedrelease preparations. It blocks neuronal reuptake of dopamine and norepinephrine and antagonizes acetylcholine at neuronal nicotinic receptors. ${ }^{1}$ At therapeutic doses, bupropion is generally well-tolerated; however, common adverse effects include dry mouth, nausea, agitation and insomnia. ${ }^{1}$

\section{Clinicians should remain vigilant for signs of bupropion misuse}

Bupropion abusers report that they easily obtained the drug from physicians under the pretense of seeking an antidepressant or smoking cessation aid. ${ }^{3}$ Emerging reports also highlight bupropion misuse in correctional facilities. ${ }^{5}$ Bupropion toxicity should be considered in patients presenting with new-onset seizures of unknown cause, particularly in the context of suspected substance abuse. Nonhealing skin ulcers may reflect surreptitious injection of crushed tablets.

CMAJ invites submissions to "Five things to know about ..." Submit manuscripts online at http://mc.manuscriptcentral .com/cmaj

\section{Bupropion abuse is a growing public health problem}

Although bupropion shares some structural and pharmacologic properties with amphetamine, early research suggested the drug did not produce any psychostimulant effects. ${ }^{1}$ However, clinical experience and an increasing number of case reports describe bupropion abuse, ${ }^{2}$ including recreational ingestion, nasal insufflation of crushed tablets and, more recently, intravenous injection. ${ }^{3}$ Bupropion abusers report receiving a "high" similar to cocaine abuse, but of lesser intensity.

\section{Seizures are a hallmark of toxicity}

Bupropion lowers the seizure threshold, even at therapeutic doses of 150 $450 \mathrm{mg} / \mathrm{d} .{ }^{1}$ Acute overdose typically produces seizures within a few hours after ingestion, although seizure onset may be delayed up to 24 hours in patients who ingest extended-release preparations. ${ }^{6}$ The median dose associated with seizures is about 4.4 g. ${ }^{6}$ Other reported signs of toxicity include lethargy, tremor, vomiting and agitation. ${ }^{7}$ Associated cardiac toxicity includes sinus tachycardia, and massive overdose can cause widening of the QRS complex, ventricular dysrhythmias and cardiovascular collapse. ${ }^{8}$ Death can occur. Although reported data are limited, they suggest that less than $0.5 \%$ of reported cases of bupropion overdose result in death. ${ }^{9}$

See references, Appendix 1, www.cmaj.ca /lookup/suppl/doi:10.1503/ cmaj.131534/-/DC1

Competing interests: Nathan Stall is a freelance news writer for and serves on the editorial advisory board of CMAJ.

This article has been peer reviewed.
Management of bupropion overdose is largely supportive

For all cases of bupropion overdose, seizures should be anticipated and a poison control centre consulted. Treatment with activated charcoal should be considered for patients presenting within 60 minutes of ingestion in whom the risk of aspiration is low. ${ }^{10}$ Whole bowel irrigation may be considered for patients with large ingestions of sustained-release preparations. ${ }^{11}$ Seizures can usually be managed with benzodiazepines alone, ${ }^{2}$ but some patients may require barbiturates or propofol. ${ }^{11}$ Phenytoin is unlikely to work and should not be administered. ${ }^{12}$ In patients with life-threatening cardiovascular toxicity, intravenous lipid emulsion may be helpful, although evidence for its use is very limited.

Affiliations: Department of Medicine (Stall), Divisions of Emergency Medicine and of Pharmacology and Toxicology (Godwin), University of Toronto; Institute for Clinical Evaluative Sciences (Juurlink), Toronto, Ont.

Correspondence to: Nathan Stall, nathan.stall @mail.utoronto.ca

CMAJ 2014. DOI:10.1503/cmaj.131534 